See discussions, stats, and author profiles for this publication at:

https://www.researchgate.net/publication/260831003

\title{
Business Benefits or Incentive Maximization? Impacts of the Medicare EHR Incentive Program at Acute Care Hospitals
}

Article in ACM Transactions on Management Information Systems · December 2013 DOI: $10.1145 / 2543900$

\section{CITATION}

1

\section{2 authors:}

\section{Rajesh Mirani}

University of Baltimore

28 PUBLICATIONS 550 CITATIONS

SEE PROFILE
READS

76

Some of the authors of this publication are also working on these related projects: 


\title{
Business Benefits or Incentive Maximization? Impacts of the Medicare EHR Incentive Program at Acute Care Hospitals
}

\author{
RAJESH MIRANI, University of Baltimore \\ ANJU HARPALANI, Booz Allen Hamilton
}

\begin{abstract}
This study investigates the influence of the Medicare EHR Incentive Program on EHR adoption at acute care hospitals and the impact of EHR adoption on operational and financial efficiency/effectiveness. It finds that even before joining the incentive program, adopter hospitals had more efficient and effective Medicare operations than those of non-adopters. Adopters were also financially more efficient. After joining the program, adopter hospitals treated significantly more Medicare patients by shortening their stay durations, relative to their own non-Medicare patients and also to patients at non-adopter hospitals, even as their overall capacity utilization remained relatively unchanged. The study concludes that many of these hospitals had implemented EHR even before the initiation of the incentive program. It further infers that they joined this program with opportunistic intentions of tapping into incentive payouts which they maximized by taking on more Medicare patients. These findings give credence to critics of the program who have questioned its utility and alleged that it serves only to reward existing users of EHR technologies.
\end{abstract}

Categories and Subject Descriptors: K.4.1 [Computers and Society]: Public Policy Issues

General Terms: Management, Measurement, Performance

Additional Key Words and Phrases: Electronic health records, electronic medical records, information technology adoption, information technology implementation, Medicare EHR Incentive Program, opportunism, organizational change, perverse incentives

ACM Reference Format:

Mirani, R. and Harpalani, A. 2013. Business benefits or incentive maximization? Impacts of the Medicare EHR Incentive Program at acute care hospitals. ACM Trans. Manage. Inf. Syst. 4, 4, Article 20 (December 2013), 19 pages.

DOI : http://dx.doi.org/10.1145/2543900

\section{INTRODUCTION}

In recent years, electronic health records (EHR), also known as electronic medical records (EMR), have been championed as a next-generation, technology-based solution for effectively addressing a variety of concerns with the public health system [Winston and Medlin 2011]. Touted benefits of EHR include seamless information availability and exchange, fewer medical errors, drug compliance, patient and physician satisfaction, lowered healthcare costs, as well as improved quality of clinical outcomes [Furukawa et al. 2010; Hillestad et al. 2005; Hochstadt and Keyt 2009; Kazley et al. 2012; Song et al. 2011]. The pitch for universal EHR usage has grown to the point where federal and state governments now provide incentives and tax breaks to healthcare providers for purchasing and implementing clinical technologies such as EHR applications.

Author's address: R. Mirani; email: rmirani@ubalt.edu.

Permission to make digital or hard copies of part or all of this work for personal or classroom use is granted without fee provided that copies are not made or distributed for profit or commercial advantage and that copies show this notice on the first page or initial screen of a display along with the full citation. Copyrights for components of this work owned by others than ACM must be honored. Abstracting with credit is permitted. To copy otherwise, to republish, to post on servers, to redistribute to lists, or to use any component of this work in other works requires prior specific permission and/or a fee. Permissions may be requested from Publications Dept., ACM, Inc., 2 Penn Plaza, Suite 701, New York, NY 10121-0701 USA, fax +1 (212) 869-0481, or permissions@acm.org.

(C) 2013 ACM 2158-656X/2013/12-ART20 $\$ 15.00$

DOI : http://dx.doi.org/10.1145/2543900 
Despite this, healthcare providers have been somewhat reluctant to embrace records automation technologies. An analysis of the 2009 American Hospital Association (AHA) information technology (IT) survey found that only $11.4 \%$ of all hospitals met all of the core EHR implementation criteria as defined by the survey, although many more had adopted specific components or elements of comprehensive EHR systems [Blavin et al. 2010]. Long-term, acute care hospitals have continued to exhibit particularly low adoption rates [Wolf et al. 2012], as have small, nonteaching, rural hospitals [DesRoches et al. 2012] -often half that of urban, teaching hospitals. Cost barriers, technical challenges, resistance from medical professionals, and unconvincing evidence of tangible returns on EHR investments are often cited as reasons for this inertia [Khoumbati and Themistocleous 2006; Song et al. 2011]. However, a recent study reported that EHR adoption among acute care hospitals had more than tripled between 2009 and 2012, reaching approximately 45\% [Charles et al. 2013].

A large part of public healthcare policy turns on two assumptions in this regard. The first assumption is that the rate of EHR diffusion among healthcare individuals and organizations can be accelerated by legislatively mandated incentives. The second assumption is that incentivized adoption and implementation will lead to beneficial business outcomes. Both are unproven assumptions, representing a neglected area in the literature. Much has been written on the roles of specific factors in the employment and the use of EHR by healthcare provider organizations. Some issues addressed include overcoming change resistance [Nov and Schecter 2012], influencing adoption attitudes [Angst and Agarwal 2009], internalizing adoption intent [Hennington et al. 2009], shaping usage through individual actions [Jensen et al. 2009], selecting appropriate enterprise application strategies [Fareed et al. 2012], generating critical mass [Ayers et al. 2009], ensuring technology usability [Schumacher and Jerch 2012; Swanson and Lind 2011], improving task-technology fit [El-Gayar et al. 2010], and creating process and workflow integration [Hoffmann 2009]. However, the link between incentives and EHR adoption has never been examined, although the general literature on incentives is replete with reports of unintended consequences and perverse outcomes (e.g., [Ginsburg and Grossman 2005; Naylor et al. 2012]). Further, while some studies have in fact tested the connection between EHR and organizational performance, their findings have been inconclusive [East 2005; Helton and Hsu 2012; Kazley et al. 2011]. The purpose of the present study is to explore the three-way connection between such legislated EHR incentives, EHR adoption, and the realization of tangible business benefits, such as increased efficiency and effectiveness.

This translates into two broad objectives. The first objective is to characterize healthcare providers that respond to incentives by adopting EHR. The literature suggests that EHR adoption decisions may be influenced by operational and financial concerns [Ginn et al. 2011; Zhivan and Diana 2012]. Additionally, these concerns fall into one of two categories: efficiency-related and effectiveness-related. Examples of efficiency-related concerns typically have to do with the high costs of care (e.g., [Shin et al. 2012]), while effectiveness-related concerns include objectives such as the provision of high-quality care (e.g., [Anonymous 2009]). This characterization will therefore look to differentiate between adopters and non-adopters in terms of operational efficiency, operational effectiveness, financial efficiency, and financial effectiveness. One expectation might be that organizations performing poorly along one or more of these measures would respond to resulting exigencies by adopting EHR systems. Resourcedependency theory [Pfeffer and Salancik 1978] seems to support this assertion, with the rationale that poor performance results in the loss of organizational autonomy and power vis-à-vis the environment, both of which may be recovered considerably by enhancing information sharing abilities through EHR adoption and usage. On the other hand, it can be argued that only well-performing organizations would possess 
the organizational culture, financial power, and management expertise necessary to embark upon EHR systems adoption. This opposite viewpoint appears to be bolstered by institutional theory [DiMaggio and Powell 1983], with the reasoning that successful organizations would consolidate and perpetuate their leading marketplace status by continuing to pursue innovative practices, including EHR systems implementation. The resource-dependency reasoning would therefore suggest that EHR adopter organizations tend to lag in terms of organizational efficiency and effectiveness, while the institutional theory logic would argue exactly the opposite, that is, such organizations tend to be high achievers. Either way, adopters are expected to be significantly different from non-adopters on organizational efficiency and effectiveness scales.

The second and main objective of the study is to test whether EHR adoption and implementation in turn leads to improved efficiency and effectiveness. The implementation and use of healthcare technologies is said to lead to greater efficiencies, more patient safety, and better quality of health care [Jha et al. 2009].

The context selected for the study is the ongoing Medicare EHR Incentive program, and the setting is acute care hospitals. Under Stage 1 of this multistage, multiyear program designed to encourage widespread EHR diffusion and use among healthcare providers, Medicare provided hospitals with incentive payments if they fulfilled the following conditions: (i) registered in the program, (ii) adopted certified EHR as defined by the program, and (iii) demonstrated 'meaningful use' as defined by the program. For this study, therefore, adopter hospitals were defined as those who had fulfilled these three conditions and received incentive payments as a result. The following section provides more details on the program and articulates the hypotheses of this study.

\section{CONTEXT AND HYPOTHESES}

As part of the American Recovery and Reinvestment Act of 2009 (ARRA), the Health Information Technology for Economic and Clinical Health Act (HITECH Act) was legislated in order to encourage the widespread adoption and implementation of EHR and to enhance the overall efficiency and effectiveness of the healthcare system [Hamelburg 2009]. The HITECH Act set aside approximately $\$ 20$ billion for this express purpose, to be disbursed among medical professionals and hospitals as incentives to adopt and use EHR [MacKinnon and Wasserman 2009]. These funds were to be administered through the Centers for Medicare \& Medicaid Services (CMS), which instituted two incentive programs towards this end: the Medicare EHR Incentive Program and the Medicaid EHR Incentive Program. This article addresses the former program.

The Medicare EHR Incentive Program predicates the distribution of incentives to providers on the demonstration of 'meaningful use' of certified EHR technology. Meaningful use has been defined by CMS as comprising of three components: (a) a meaningful manner of certified EHR use, (b) for electronic exchange of health information to improve health care quality, and (c) as evidenced by certain clinical quality measures $(\mathrm{CQMs})$. Both meaningful use demonstration and incentives payments are to be spread out over several 'stages' in a period of five years, beginning in 2011. For stage 1, eligible professionals (EPs) and eligible hospitals (EHs) have been provided separate sets of criteria in the form of various objectives and measures to demonstrate meaningful use.

While these incentive programs were announced in the 2009/2010 time frame, registration and incentives disbursement officially began in 2011. To date, hundreds of EPs and EHs have sought and received EHR incentives. CMS maintains detailed datasets on thousands of professionals and hospitals, including 'identifiable' information on providers who have received EHR incentives. Aside from this information, the CMS datasets also include basic contact information, measures of provider size, as well as some cost and revenue measures. While all of this information is spread out among 
multiple datasets and files, it may be easily cross referenced through the presence of a common identifier field containing unique, 'permanent' values assigned by CMS.

The present study extracts and combines pertinent information from these datasets in order to test eight hypotheses. The essence of Hypotheses H1 through H4 is that hospitals adopting certified EHR and filing for associated Medicare incentives will be significantly different from non-adopters in terms of organizational and effectiveness, even before EHR adoption. The essence of Hypotheses H5 through H8 is that adopting hospitals ultimately experience better efficiency and effectiveness outcomes than hospitals that do not implement certified EHR. Both business efficiency and effectiveness are expressed along two dimensions: operational and financial. The eight hypotheses are therefore stated as follows.

- H1. Hospitals that adopt certified EHR technology are significantly different from non-adopters in terms of operational efficiency.

- H2. Hospitals that adopt certified EHR technology are significantly different from non-adopters in terms of operational effectiveness.

- H3. Hospitals that adopt certified EHR technology are significantly different from non-adopters in terms of financial efficiency.

- H4. Hospitals that adopt certified EHR technology are significantly different from non-adopters in terms of financial effectiveness.

- H5. Implementing certified EHR technology leads to increased operational efficiency.

- H6. Implementing certified EHR technology leads to increased operational effectiveness.

- H7. Implementing certified EHR technology leads to increased financial efficiency.

- H8. Implementing certified EHR technology leads to increased financial effectiveness.

\section{OPERATIONALIZATION}

The hypotheses in the research model were tested on hospitals listed in the 2008 and 2010 data obtained from the 'Data and Reports' and 'Hospital Cost Report' pages of the Centers for Medicare \& Medicaid Services (CMS) website at cms.gov. (The Analysis and Results section discusses the rationale behind the selection of these two specific years.) Seven separate 'comma delimited' (.csv format) data files were identified and isolated from datasets downloaded from the CMS site. An eighth file was obtained from the National Bureau of Economic Research (NBER) at nber.org. All eight files were loaded and saved in Microsoft Excel format. The first file, EHProvidersPaidByEHRProgram-March2012.csv, contained information records on more than eight hundred eligible hospitals that had applied for, and been granted, Stage 1 EHR incentives as of March, 2012. This file was de-identified in order to discard all identifiable information, for example, hospital name, address, and phone number, leaving a numerical identifier called CMS Certification Number (CCN), as the sole attribute in the modified table. CMS uses this common identifier in all of its files in order to facilitate cross-referencing and longitudinal analyses.

The remaining seven files contained disparate information on more than five thousand Medicare hospitals, including the eight hundred plus hospitals certified and incentivized for meaningful EHR use, as previously mentioned. Of these six sources, the second and third files, IME_GME2008.csv and IME_GME2010.csv, pertaining, respectively, to fiscal years 2008 and 2010, contained basic operational data relating to hospital size and usage statistics. The fourth and fifth files, CSTS_CHRGS2008.csv and CSTS_CHRGS2010.csv, comprised of data on ancillary hospital costs, as well as ancillary inpatient and outpatient charges (amounts charged). The sixth and seventh files, 
Bad_debts2008.csv and Bad_debts2010.csv, consisted of fields summarizing bad debts held by the hospitals, separately for their inpatient and outpatient businesses. Finally, the eighth file, HOSPITAL_PROVIDER_ID_INFO.csv, obtained from NBER, included data pertaining to two control type variables—rural/urban/other location-and type of ownership. All eight files included the common CCN identifier field.

These files were trimmed to remove certain fields that were irrelevant to the analysis. While many fields were retained in their original form, others were used in various combinations with each other to generate new, computed fields more meaningful for the analysis.

Appendix A summarizes the eight source files, the data fields extracted from each, their modified short names as analysis variables, and brief descriptions. Appendix B provides a similar summary of the computed fields. Both tables also outline the research constructs each field was assigned to represent.

Operational efficiency was represented by the three variables BEDUTIL, STAYMED, and STAYGEN, as follows.

- BEDUTIL was the ratio of total patient-days used to total patient-days available.

- STAYMED was the average days of stay per Medicare patient.

- STAYGEN was the average days of stay per patient.

Financial efficiency was represented by the two variables UNITCOSTS and MARGIN, as follows.

- UNITSCOSTS was the average costs of ancillary services per patient.

- MARGIN was the ratio of total inpatient and outpatient charges minus total ancillary costs, to total ancillary costs.

Operational effectiveness was represented by the five variables MEDDAYS, PROPMED, TOTDAYS, MEDPATIENTS, and TOTPATIENTS, as follows.

- MEDDAYS was the average number of bed-days used by Medicare patients.

- PROPMED was the ratio of the number of Medicare bed-days used to the number of total bed-days used.

- TOTDAYS was the average number of bed-days used by all patients.

- MEDPATIENTS was the total number of discharged Medicare patients.

- TOTPATIENTS was the total number of discharged patients.

Finally, financial effectiveness was represented by the two variables INDEBT and OUTDEBT, as follows.

- INDEBT was the total amount of inpatient bad debts.

- OUTDEBT was the total amount of outpatient bad debts.

Altogether, these represented a total of twelve business benefit variables. In addition, four other variables were included as controls. These were OWNERSHIP (government, proprietary, or voluntary), LOCATION (urban, rural, or other), TOTEMPS (total number of hospital employees), and TOTBEDS (total number of hospital beds).

The eight modified Excel files were subsequently merged together and analyzed using a statistical package called XLSTAT. The consolidated table consisted of records on more than 5,000 hospitals. Before analysis, the combined Excel file was systematically checked for outliers, extreme values, and obvious errors. Outliers were detected by successively sorting the file by each field in turn and then cross-comparing all field values in the resulting low and high records with those in adjacent records. This check of the data revealed three questionable records. One contained an inordinately high value for number of hospital employees $(18,062)$, given the values of the other fields in that record. Another suggested an improbable hospital bed utilization rate of more 
than $100 \%$. A third problematic record resulted in an excessively high computed profit margin for ancillary services $(688833600 \%)$. The fields corresponding to these three ambiguous pieces of information were replaced with blank values.

\section{ANALYSIS AND RESULTS}

The premise behind Hypotheses H1 through H4 was that hospitals that had adopted certified EHR technology would have significantly higher or lower scores than nonadopting hospitals on operational and financial performance scales, both in terms of efficiency and effectiveness. Therefore, the analysis for testing these hypotheses would need to treat the twelve business benefit measures plus the four controls as continuous independent variables, and the implementation of certified EHR as the lone, categorical, dependent variable. Further, since hypotheses $\mathrm{H} 1$ through $\mathrm{H} 4$ pertained to the 'pre-treatment' context, the data for this analysis would need to be based on the time period immediately preceding the EHR Incentive program. Given that the incentive program was part of the Recovery Act of 2009, it was decided that these hypotheses would be tested on FY 2008 data as the baseline.

Both discriminant analysis and logistic regression are well suited to these analysis requirements. However, logistic regression is considered a less restrictive and superior test, particularly when the dependent variable is binary in nature. Accordingly, a logistic regression analysis, based on maximization of the likelihood function using the Newton-Raphson algorithm, was run with CERTIFY as the binary, dependent variable, which took on values of 0 or 1 depending on whether or not the hospital had implemented certified EHR. The independent variables were comprised of the set of twelve measures corresponding to the four sets of objectives plus the four controls mentioned earlier.

As the combined data file had missing values scattered throughout, two alternate logistic regression analyses were explored: one that completely dropped all records with any missing values, and another that estimated missing values based on the nearest neighbor method. Both analyses were programmed to conduct validation checks of their respective regression models on 300 randomly selected data records. The inherent advantage of the former method lies in its preservation of data integrity, while the latter method would be preferable in terms of sample size. It was found that the former method resulted in a tighter, more parsimonious set of explanatory variables relative to the latter (four versus thirteen), and that this smaller variable set allowed for a much clearer interpretation of the types of hospitals that had opted for certification. It is the former analysis, therefore, that is reported here. This analysis removed 2,453 observations due to missing information, leaving 3,352 non-certified hospital records and 769 certified hospital records, for a total of 4,121 records. After setting aside the 300 records for model validation, these sample sizes dropped to 3,108 and 713, respectively, for a total of 3,821 records. Tables I and II summarize the descriptive statistics for all variables used to test Hypotheses $\mathrm{H} 1-\mathrm{H} 4$.

Using a forward stepwise logit model, a 95\% confidence interval, and entry and removal probabilities of 0.1 and 0.2 , respectively, the logistic regression model converged in seven iterations. The following independent variables were found to have significant effects: STAYMED, UNITCOSTS, MEDDAYS, and LOCATION-U (i.e., urban location). In addition, the variables OUTDEBT and LOCATION-R made it into the model, but neither was statistically significant. All other independent variables were discarded by the model. The standardized coefficients for MEDDAYS and LOCATION-U were in the positive range, while those for STAYMED and UNITCOSTS were in the negative range. Table III summarizes the standardized coefficients, standard errors, and Wald Chi-Square statistics for the various parameters. 
Table I. FY 2008 Quantitative Variables in Tests of Hypotheses $\mathrm{H} 1-\mathrm{H} 4$

\begin{tabular}{|lcrrrr|}
\hline Variable & Observations & \multicolumn{1}{c}{ Minimum } & \multicolumn{1}{c}{ Maximum } & \multicolumn{1}{c|}{ Mean } & Standard deviation \\
\hline TOTEMPS & 3821 & 1.000 & 18260.720 & 913.140 & 1266.185 \\
TOTBEDS & 3821 & 2.000 & 1869.000 & 159.831 & 167.869 \\
TOTDAYS & 3821 & 16.000 & 514626.000 & 36674.518 & 47177.870 \\
BEDUTIL & 3821 & 0.004 & 1.553 & 0.530 & 0.213 \\
MEDDAYS & 3821 & 4.000 & 191036.000 & 13803.923 & $16,486.499$ \\
PROPMED & 3821 & 0.001 & 0.961 & 0.460 & 0.172 \\
MEDPATIENTS & 3821 & 1.000 & 35695.000 & 2533.611 & 2894.306 \\
STAYMED & 3821 & 1.000 & 502.000 & 6.287 & 9.819 \\
TOTPATIENTS & 3821 & 3.000 & 107835.000 & 7584.372 & 9213.821 \\
STAYGEN & 3821 & 1.113 & 1468.608 & 7.420 & 42.480 \\
UNITCOSTS & 3821 & $\$ 11.78$ & $\$ 1,859,259.27$ & $\$ 20,380.42$ & $\$ 54,312.03$ \\
MARGIN & 3821 & -0.992 & 3506.050 & 6.899 & 66.661 \\
INDEBT & 3821 & $-\$ 11,634.00$ & $\$ 10,794,720.00$ & $\$ 335,281.24$ & $\$ 513,550.02$ \\
OUTDEBT & 3821 & $-\$ 16,679.00$ & $\$ 5,146,574.00$ & $\$ 220,235.00$ & $\$ 343,362.58$ \\
\hline
\end{tabular}

Table II. FY 2008 Qualitative Variables in Tests of Hypotheses $\mathrm{H} 1-\mathrm{H} 4$

\begin{tabular}{|llcr|}
\hline Variable & Categories & Frequencies & Percent \\
\hline LOCATION & Urban & 129 & $3.38 \%$ \\
& Rural & 57 & $1.49 \%$ \\
& Other & 3,635 & $95.13 \%$ \\
\hline OWNERSHIP & Government & 749 & $19.60 \%$ \\
& Private & 978 & $25.60 \%$ \\
& Voluntary & 2,094 & $54.80 \%$ \\
\hline
\end{tabular}

Figure 1 presents a visual representation of the standardized coefficients, reflecting the relative strengths of the model variables. Aside from the control variable LOCATION-U, the three other predictor variables collectively represent-in declining order of absolute magnitude-operational efficiency, financial efficiency, and operational effectiveness. The values of the standardized coefficients suggest that certified hospitals receiving EHR incentives handled more Medicare patient-days overall but had fewer days of stay per Medicare patient on average, and enjoyed lower ancillary costs per patient. Such hospitals were also more often located in urban areas. In general terms, therefore, these hospitals were more operationally and financially efficient, as well as more operationally effective. These findings support Hypotheses H1, H2, and $\mathrm{H} 3$, but not Hypothesis $\mathrm{H} 4$.

Hypotheses H5 through H8 comprised the core of this study. Their postulations were that hospitals receiving Medicare incentives for implementing certified EHR would experience greater boosts in efficiency/effectiveness, relative to other hospitals. Testing the presence of these business benefits called for first identifying a post-treatment year, by which such benefits could be reasonably expected to have materialized. Since the available Medicare data do not indicate the precise time period in which each hospital actually received EHR incentives, the prudent course of action would have been to peg realized benefits/outcomes to the most recent past year at the time of writing these results, which was FY 2011. In addition, official participation and payouts in this program began only in early 2011. However, as FY 2011 had not yet been published, FY 2010 was selected to serve as the outcomes year, or, as the anchor for post-treatment measures.

Two different sets of tests were employed to look for evidence of the business benefits of certified EHR technology suggested by Hypotheses H5 through H8. CERTIFY 
Table III. Logistic Regression of CERTIFY on FY 2008 Data: Hypotheses H1-H4

\begin{tabular}{|c|c|c|c|}
\hline Variable & Standardized Coefficient & Standard Error & Wald Chi-Square \\
\hline \multicolumn{4}{|l|}{ Control variables } \\
\hline$\bullet \quad$ OWNERSHIP-V & 0.000 & 0.000 & N/A \\
\hline - OWNERSHIP-P & 0.000 & 0.000 & N/A \\
\hline - OWNERSHIP-G & 0.000 & 0.000 & N/A \\
\hline - LOCATION-U & 0.100 & 0.018 & $31.646^{*}$ \\
\hline - $\quad$ LOCATION-R & -0.009 & 0.019 & 0.257 \\
\hline - LOCATION-O & 0.000 & 0.000 & N/A \\
\hline - TOTEMPS & 0.000 & 0.000 & N/A \\
\hline - TOTBEDS & 0.000 & 0.000 & N/A \\
\hline \multicolumn{4}{|l|}{ Operational efficiency } \\
\hline$\bullet \quad$ BEDUTIL & 0.000 & 0.000 & N/A \\
\hline - STAYMED & -1.038 & 0.109 & $90.300 *$ \\
\hline - $\quad$ STAYGEN & 0.000 & 0.000 & N/A \\
\hline \multicolumn{4}{|l|}{ Operational effectiveness } \\
\hline - MEDDAYS & 0.233 & 0.023 & $101.446 *$ \\
\hline - $\quad$ PROPMED & 0.000 & 0.000 & N/A \\
\hline - $\quad$ TOTDAYS & 0.000 & 0.000 & N/A \\
\hline - $\quad$ MEDPATIENTS & 0.000 & 0.000 & N/A \\
\hline - $\quad$ TOTPATIENTS & 0.000 & 0.000 & N/A \\
\hline \multicolumn{4}{|l|}{ Financial Efficiency } \\
\hline • UNITCOSTS & -0.469 & 0.108 & $19.009 *$ \\
\hline - $\quad$ MARGIN & 0.000 & 0.000 & N/A \\
\hline \multicolumn{4}{|l|}{ Financial Effectiveness } \\
\hline - INDEBT & 0.000 & 0.000 & N/A \\
\hline - OUTDEBT & -0.040 & 0.021 & 3.410 \\
\hline
\end{tabular}

$n_{\mathrm{CERTIFY}(0)}=3108 ; n_{\mathrm{CERTIFY}(1)}=713$

${ }^{*} p \leq 0.0001$

was the predictor variable in both sets. The first set comprised of separate analyses of covariance (ANCOVAs) for the FY 2010 values of each of the twelve business benefit variables. A single covariate was added as a baseline control to each analysis, and this was the 2008 value of the respective benefit variable. For example, the covariate for the ANCOVA on the average number of bed-days used by Medicare patients (MEDDAYS2010) was MEDDAYS-2008, and so on. In the second set of analyses, two-tailed t-tests were run on differences between paired FY 2010 data and FY 2008 data (i.e., between the outcomes year and the baseline year), along the twelve business benefit variables, to test for equality of means for certified versus non-certified hospitals. Table IV summarizes the descriptive statistics for the variables used to test Hypotheses H5-H8.

The results of the ANCOVAs comprising the first set of tests are presented in Table V. After controlling for 2008 baseline covariates, statistically significant differences between certified and noncertified hospitals were detected for nine of the twelve 2010 benefit variables. A particularly interesting aspect of these results was that the operational efficiency and effectiveness of certified hospitals went up even further after EHR certification, but selectively more so for Medicare patients than for nonMedicare patients. In terms of effectiveness, for instance, a significant value of -0.016 for the standardized coefficient of MEDPATIENTS-10 (annual number of Medicare patients processed in 2010) under CERTIFY (0) statistically reinforced the finding that the average value of MEDPATIENTS at certified hospitals increased $1.2 \%$ from $3,005.36$ to 3,042.41 between 2008 and 2010, even as the corresponding average at noncertified hospitals dropped $2.55 \%$ from $1,584.83$ to $1,544.49$ during this period. In 


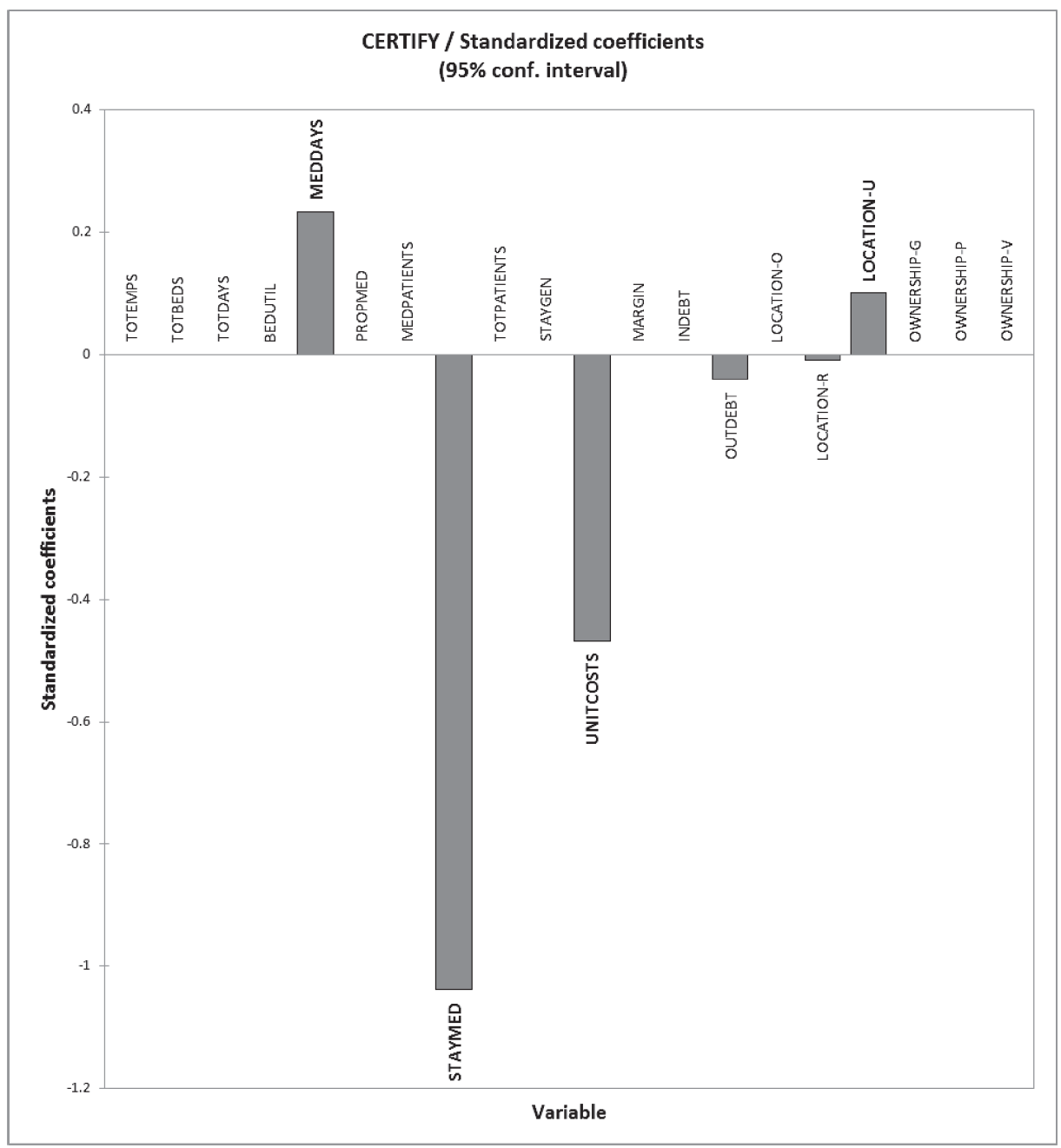

Fig. 1. Standardized parameter coefficients of logistic regression. (Bolded variables represent statistically significant coefficients.)

contrast, changes to the averages for non-Medicare patients during this same period were much smaller at both certified and noncertified hospitals, respectively, from $6,426.69$ to $6,456.48$ (an increase of $0.46 \%$ ), and from 3,057.46 to 3,056.62 (a decrease of $0.027 \%$ ). Clearly, certified hospitals were seeing more Medicare patients after joining the incentive program.

In terms of efficiency, too, a significant value of 0.011 for the standardized coefficient of STAYGEN-10 (average stay duration for all patients in 2010) under CERTIFY (0) provided statistical support for the observation that the average duration of stay for Medicare patients at certified hospitals dropped $4.62 \%$, from 5.10 days to 4.89 days, possibly reflecting increased efficiency, while at noncertified hospitals, the average stay for Medicare patients rose $0.34 \%$, from 8.88 days to 8.91 days. These numbers contrasted with opposite trends for non-Medicare patients: from 4.07 to 4.18 (an increase of $2.7 \%$ ) at certified hospitals, and from 14.93 to 11.95 (a decrease of $20 \%$ ) at 
Table IV. FY 2010 Variables in Tests of Hypotheses H5-H8

\begin{tabular}{|lcrrrr|}
\hline Variable & Observations & Minimum & \multicolumn{1}{c}{ Maximum } & \multicolumn{1}{c|}{ Mean } & Standard deviation \\
\hline TOTDAYS & 4294 & 0.000 & 548711.000 & 26358.515 & 41180.099 \\
BEDUTIL & 4294 & 0.000 & 1.375 & 0.505 & 0.219 \\
MEDDAYS & 4294 & 0.000 & 199112.000 & 9910.067 & 14313.078 \\
PROPMED & 4294 & 0.000 & 0.947 & 0.474 & 0.219 \\
MEDPATIENTS & 4294 & 0.000 & 37157.000 & 1738.429 & 2601.813 \\
STAYMED & 4294 & 0.000 & 434.600 & 8.429 & 10.818 \\
TOTPATIENTS & 4294 & 1.000 & 82900.000 & 5167.293 & 7825.094 \\
STAYGEN & 4294 & 0.000 & 4555.250 & 10.114 & 72.106 \\
UNITCOSTS & 4294 & $\$ 0.00$ & $\$ 28,215,217.76$ & $\$ 38,441.67$ & $\$ 525,222.64$ \\
MARGIN & 4294 & -0.996 & 1394.056 & 6.369 & 48.203 \\
INDEBT & 4294 & $\$ 0.00$ & $\$ 4,454,436.00$ & $\$ 274,898.79$ & $\$ 527,545.88$ \\
OUTDEBT & 4294 & $-\$ 625.00$ & $\$ 3,574,995.00$ & $\$ 165,971.60$ & $\$ 323,690.49$ \\
\hline
\end{tabular}

noncertified hospitals. It was clear, therefore, that after joining the incentive program, certified hospitals had selectively sped up their turnover of Medicare patients.

Likewise, the significant negative coefficients of -0.008 and -0.007 under CERTIFY(0), respectively for the annual number of bed-days used collectively by Medicare patients (MEDDAYS-10) and the annual number of bed-days used collectively by all patients (TOTDAYS-10), underscored the fact that relative to certified hospitals, the rate of decline in capacity utilization between 2008 and 2010 was higher for noncertified hospitals. In other words, certified hospitals more successfully compensated for the loss of patient-days due to quicker turnarounds, by treating greater numbers of patients. That is, they became not just more operationally efficient but also more operationally effective following EHR implementation.

In light of all these findings, Hypotheses 5 and 6 may be said to be supported by evidence.

In terms of financial efficiency and effectiveness, however, results were largely contrary to those expected from Hypotheses 7 and 8. Neither financial efficiency nor financial effectiveness appeared to have been beneficially impacted by EHR implementation. The former was tested by means of ANCOVAs on UNITCOSTS-2010 and MARGIN-2010, and the latter by ANCOVAs on INDEBT-2010 and OUTDEBT-2010. For financial efficiency, while the results for UNITCOSTS-10 were statistically insignificant, those for MARGIN-2010 actually showed the opposite of Hypothesis 7 to be true. The significance of the standardized coefficient of 0.024 under CERTIFY(0) highlighted the fact that gross profit margins from ancillary services were higher for noncertified hospitals than certified hospitals. For financial effectiveness, both tests yielded significant results but here too showed the opposite of Hypothesis 8 to be true. The significant standardized coefficients values of -0.035 and -0.045 , respectively, for INDEBT-2010 and OUTDEBT-2010 under CERTIFY(0), suggested that the rates of increase of both inpatient debt and outpatient debt between 2008 and 2010 had been higher at certified hospitals than at noncertified hospitals. Hypotheses 7 and 8 were therefore rejected.

Table VI displays the results of the second set of tests of Hypotheses 5-8, that is, the two-tailed t-tests. These tests was run on differences between paired FY 2010 and FY 2008 data points and therefore compared certified hospitals and noncertified hospitals along changes to the twelve variables. Due to such pairing, hospitals with missing or incomplete information for either of the two years were dropped from the computations and analysis. This resulted in a somewhat different set of data points being used for the t-tests, as compared to the observations used for the ANCOVAs in the first set of analyses. Running the t-tests on this altered dataset generated slightly different 


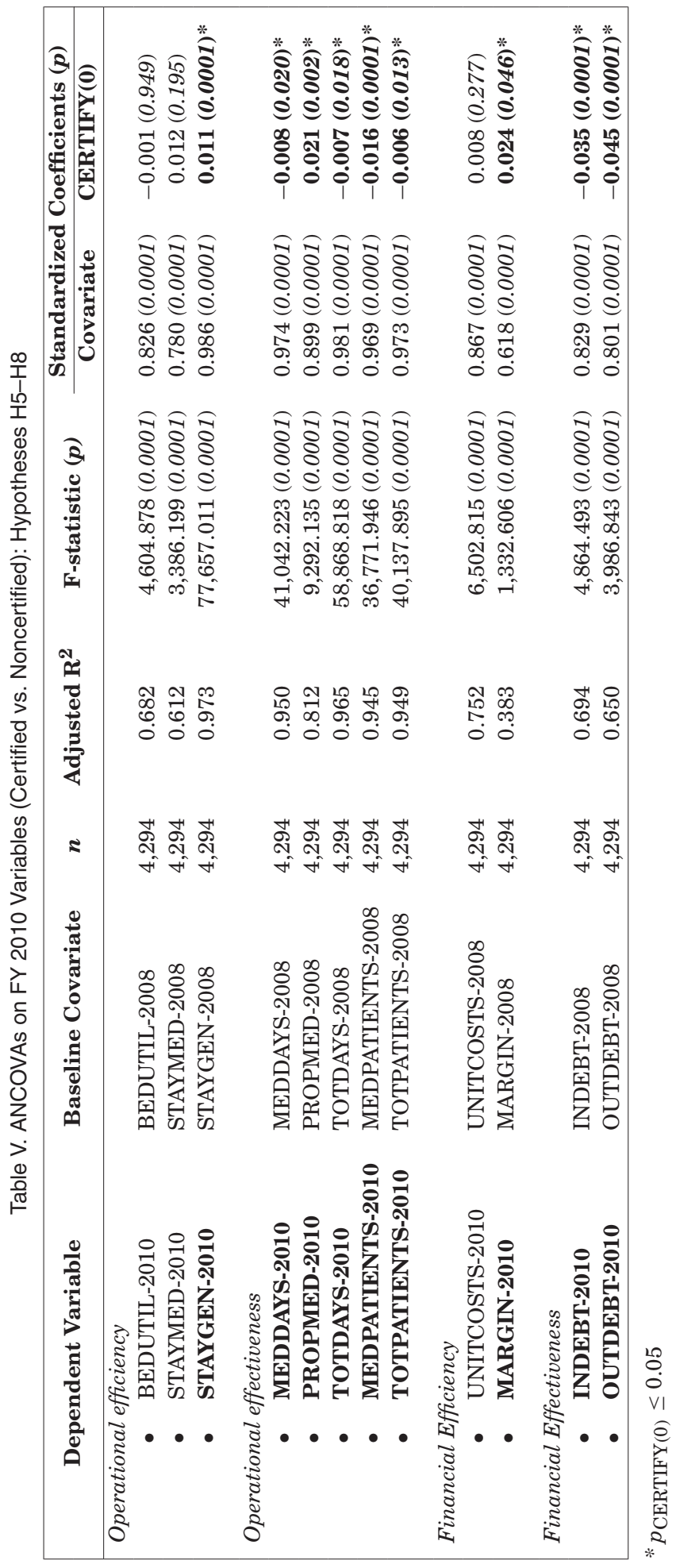

ACM Transactions on Management Information Systems, Vol. 4, No. 4, Article 20, Publication date: December 2013. 
Table VI. Two-Tailed t-Tests on FY 2010 - FY 2008 Differences: Hypotheses H5-H8

\begin{tabular}{|c|c|c|c|c|c|}
\hline Variable & $\begin{array}{l}\left(n_{\text {CERTIFY }}=0\right. \\
n_{\text {CERTIFY }}=1\end{array}$ & $t$-Statistic & $p$ & $\begin{array}{l}\text { Mean of } \\
2010-2008 \\
\text { Differences } \\
(\text { CERTIFY }=0)\end{array}$ & $\begin{array}{l}\text { Mean of } \\
2010-2008 \\
\text { Differences } \\
(\text { CERTIFY = 1) }\end{array}$ \\
\hline \multicolumn{6}{|c|}{ (Changes in Operational efficiency) } \\
\hline • DIFF_BEDUTIL & $(3,975,617)$ & 4.427 & $0.0001^{*}$ & 0.018 & -0.013 \\
\hline - DIFF_STAYMED & $(3,963,617)$ & $3.043^{*}$ & $0.002^{*}$ & 0.789 & -0.169 \\
\hline - DIFF_STAYGEN & $(3,974,617)$ & -0.386 & 0.700 & -1.140 & 0.050 \\
\hline \multicolumn{6}{|c|}{ (Changes in Operational effectiveness) } \\
\hline - DIFF_MEDDAYS & $(3,961,617)$ & 0.472 & 0.637 & -597.955 & -675.506 \\
\hline - DIFF_PROPMED & $(3,963,617)$ & $5.576^{*}$ & $0.0001^{*}$ & 0.024 & -0.010 \\
\hline - DIFF_TOTDAYS & $(3,975,617)$ & -0.672 & 0.501 & -749.803 & -485.645 \\
\hline - DIFF_MEDPATIENTS & $(3,951,617)$ & $-2.464^{*}$ & $0.014 *$ & -57.916 & 11.177 \\
\hline - DIFF_TOTPATIENTS & $(3,972,615)$ & -1.175 & 0.240 & -96.781 & 3.541 \\
\hline \multicolumn{6}{|c|}{ (Changes in Financial Efficiency) } \\
\hline - DIFF_UNITCOSTS & $(3,574,595)$ & 0.219 & 0.827 & $\$ 6,615.58$ & $\$ 2,212.95$ \\
\hline - DIFF_MARGIN & $(3,574,595)$ & 1.218 & 0.223 & 1.124 & -1.548 \\
\hline \multicolumn{6}{|c|}{ (Changes in Financial Effectiveness) } \\
\hline - DIFF_INDEBT* & $(3,554,568)$ & $-2.733^{*}$ & $0.006 *$ & $\$ 38,462.70$ & $\$ 71,804.40$ \\
\hline - DIFF_OUTDEBT* & $(2,722,537)$ & $-3.226^{*}$ & $0.001 *$ & $\$ 35,691.20$ & $\$ 70,664.00$ \\
\hline
\end{tabular}

$* p \leq 0.05$

values of average changes to each dependent variable during the two year period, relative to the change values obtained via the ANCOVAs. These different values provided the authors an opportunity to test the robustness of their findings, independent of the method used to select data points for analysis.

From the t-tests, six of the twelve changes were found to differ significantly between the two groups. They pertained, respectively, to the ratio of total patient-days used to total patient-days available (BEDUTIL; $\mathrm{p} \leq 0.0001$ ), the average days of stay per Medicare patient (STAYMED; $\mathrm{p} \leq 0.002$ ), the ratio of the number of Medicare beddays used to the number of total bed-days used (PROPMED; $\mathrm{p} \leq 0.0001$ ), the total number of discharged Medicare patients (MEDPATIENTS; $p \leq 0.014$ ), inpatient bad debts (INDEBT; $p \leq 0.006$ ), and outpatient bad debts (OUTDEBT; $p \leq 0.001$ ). It may be noted here that a Bonferroni correction for 12 simultaneous tests, if employed at a $0.05 \alpha$-level, would change the desired $\mathrm{p}$ value from 0.05 to 0.00417 , rendering insignificant the impacts of certification on two of the six significant variables, that is, MEDPATIENTS and INDEBT.

The magnitude of changes in BEDUTIL and PROPMED were found to be relatively small. The finding of significant differences for INDEBT and OUTDEBT were in line with the rejection of Hypotheses 7 and 8, as just described. Other noteworthy observations were in regards to changes to the Medicare-related variables STAYMED, PROPMED, and MEDPATIENTS over the two-year period. Noncertified hospitals lost an average of 58 Medicare patients during this time frame, compared to an average gain of eleven patients for certified hospitals. Simultaneously, the ratio of Medicare patients to all patients declined by $1 \%$ at certified hospitals, whereas this ratio went up at noncertified hospitals. Additionally, the average length of stay of Medicare patients went up by almost one full day among noncertified hospitals but declined among certified hospitals. 
Collectively, these three observations imply that certified hospitals held on to more business and that they successfully turned Medicare patients around faster. Both implications are once again in line with the results of the ANCOVAs, which had found support for Hypotheses 5 and 6. Despite their use of somewhat different data points, the results of the ANCOVAs and the t-tests, when considered together, appear to lead to the same common conclusion. That is, EHR implementation created operational advantages for certified hospitals, enabling them to effectively hold on to more businessparticularly Medicare patients-despite an economic slowdown. Concurrently, EHR may also have enabled these hospitals to process their Medicare patients more efficiently, with shorter stay durations.

A closer look at all these results, however, belies such simplistic inferences. It supports the alternative (and somewhat cynical) interpretation that although EHR implementation at certified hospitals was followed by reductions in patient stay durations and increases in the number of patients, these were not the outcomes of implementation. Rather, mitigating the high costs of EHR implementation was the real reason why certified hospitals consciously chose to turn patients around faster. Under this explanation, they did so in order to increase their Medicare patient numbers so that they could claim larger incentive payments as partial recompense for their EHR investments. This possibility is explored in detail in the next section.

\section{IMPLICATIONS AND DISCUSSION}

The results of this study support Hypotheses H1, H2, and H3, because hospitals that pursued EHR certification were found to be significantly more operationally efficient, operationally effective, and financially efficient in the first place, relative to non-adopting hospitals. They do not support H4, which postulated the presence of significant differences between the two groups in terms of financial effectiveness. The results do support Hypotheses 5 and 6, because hospitals that received incentives for certified EHR technology did in fact go on to perform better than noncertified hospitals in terms of operational efficiency and/or effectiveness. Finally, the results do not support Hypotheses 7 and 8, because financial efficiency or effectiveness did not come through as realized benefits of certified EHR technology. In summary, the implementation of certified EHR was undertaken by hospitals that were already performing better than their peers, and following EHR adoption, these hospitals gained even more of an advantage in the form of further boosts to their operational efficiency and effectiveness. Interesting implications follow.

A logical inference from the results of testing Hypotheses H1, H2, and H3 is the refutation of the premise behind the resource dependency viewpoint of EHR-adopter hospitals. Contrary to its implications, hospitals that chose to implement certified EHR technology were not encountering any particular issues with internal efficiency or effectiveness in 2008, operationally or financially. Rather, in a validation of the institutional theory viewpoint, they were already manifesting superior operational performance at that time, as evidenced by their baseline advantages over other hospitals on measures such as duration of Medicare patient stays, ancillary costs per patient, and overall business volume as measured by Medicare patient-days.

Their a priori high-performance profile suggests that certified hospitals may already have been well down the EHR implementation path when the incentive program was announced. Essentially, then, the program provided them with an opportunity to leverage their existing EHR plans and timeline, perhaps to help them counter physician/user resistance, to externally validate their specific use of EHR applications, to concretize implementation timelines, to help recoup EHR costs, or to gain market visibility. One or more such outcomes, therefore, may have been their real organizational objectives in joining the incentive program. 
Of all these possibilities, the results best support the notion that certified hospitals may have tapped into the incentive program to partially recoup the expenses of EHR implementation. Two facts are particularly noteworthy here. First, the average durations of their Medicare patients' hospital stays declined between 2008 and 2010, while stay durations at noncertified hospitals went up during the same period. Second, despite turning around patients faster, their bed utilization ratios barely showed any change between these two years. Taken together, these facts hint at a mechanism in action other than sheer operational efficiency or greater patient demand. An efficiency-driven post-EHR-implementation scenario would have significantly reduced bed utilization ratios in conjunction with reduced patient stays. On the other hand, a demand-driven scenario would have significantly increased bed utilization ratios, with or without reduced patient stays. Neither of these was actually the case. Instead, certified hospitals basically processed more patients without significantly affecting overall capacity utilization, whose mean consistently hovered around the 50\% mark. While this may be explainable in terms of extraneous constraints, such as scheduling or staffing considerations, other facts discount that particular possibility. These are the twin observations that while the numbers of Medicare patients processed by certified hospitals went up considerably between 2008 and 2010, non-Medicare patients witnessed a much smaller increase during this period. This represented a disproportionate circumstance with no parallel in the relatively proportionate declines of both Medicare and non-Medicare patients at noncertified hospitals. The only possible explanation, then, is that certified hospitals had intentionally chosen to increase the numbers of their Medicare patients, by turning them around faster. The ostensible rationale behind their deliberate actions in this regard is best understood by means of a closer look at the incentive program itself.

Under the program, the 'preliminary incentive payment' to acute care inpatient hospitals consists of an 'initial amount,' adjusted for various factors such as total inpatient bed-days, Medicare inpatient bed-days, total charges, charity care, etc. This initial amount is comprised of a base payment of $\$ 2,000,000$, plus a graded payment of $\$ 200$ for each Medicare patient discharged, but only for total annual discharge numbers exceeding a lower threshold of 1,149 patients, and up to a total of 23,000 discharged patients. By this method, a hospital that processed 1,149 patients annually would receive no more than $\$ 2$ million, while a hospital that processed 23,000 patients could stand to gain as much as $\$ 4.6$ million. The graded payments system for the preliminary incentive therefore provides a powerful explanation for the actions of certified hospitals in increasing their sheer numbers of patients discharged without affecting bed utilization figures, that is, by shortening patient stay duration, even as stays at other hospitals went up. These hospitals were engaging in an ex post facto maneuvers to use the system to their advantage, that is, to maximize their incentive payouts.

Such implications call into question the utility of the EHR incentive program in diffusing records storage and exchange automation technologies to a wider base of healthcare organizations. Critics of the program have alleged that the incentive program serves only to reward existing users of such technologies, that is, organizations that already had EHR systems in place before the start of the incentive program (e.g., [Terry 2011]). The results of this study give credence to this claim. First, they convincingly demonstrate that adopting hospitals had superior performance profiles even before joining the program. Second, they all but eliminate the likelihood that the further gains in operational efficiency and effectiveness following EHR implementation were actually attributable to the program itself. Third, a logical analysis of the findings supports a scenario in which certified hospitals tapped into the EHR incentive program simply to claim payments, and undertook deliberate actions to selectively process more Medicare patients, thus maximizing their payouts. 
Opportunism as an organizational phenomenon in response to financial incentive programs is well documented in the literature. For example, case studies of the payment-by-results $(\mathrm{PbR})$ incentive program in the U.K.'s National Health Service (NHS) concluded that funding under such a system provided strong impetus for healthcare providers to artificially increase hospital activity because they expected to be rewarded for these increases [Mannion et al. 2008]. The study also noted that there was a danger that these manipulative mechanisms could spiral out of control and improperly influence demand as an unintended consequence. Similar conclusions were derived by a study of an Activity-Based Financing (ABF) hospital payment system in Norway [Kjerstad 2003]. It found that this prospective method of payments created an incentive for hospitals to increase production volume, that is, number of hospital patients treated. Likewise, other studies have also noted perverse effects of prospective financial incentives at hospitals, including reduced quality of care [Rogers et al. 1990] and decline in length of stay [O'Reilly et al. 2012]. While a general reduction in length of stay is often considered a positive outcome indicating that patients have received better quality of care and been stabilized sooner, the selective reduction of stay durations for Medicare patients only as evidenced in this study implies the presence of unintended consequences.

In conclusion, while the findings of this article shed a less than favorable light on the short- and medium-term impacts of the Medicare EHR Incentive Program, it must be noted that these findings in no way minimize the long-term contributions of EHR technologies and applications for both providers and patients. A widespread diffusion of these technologies will undoubtedly create a vastly integrated infrastructure, resulting in a number of desired consequences, including faster, more accurate access to patient information, better coordination of care, reduced Medicare fraud, waste, and abuse, and improved overall outcomes. 


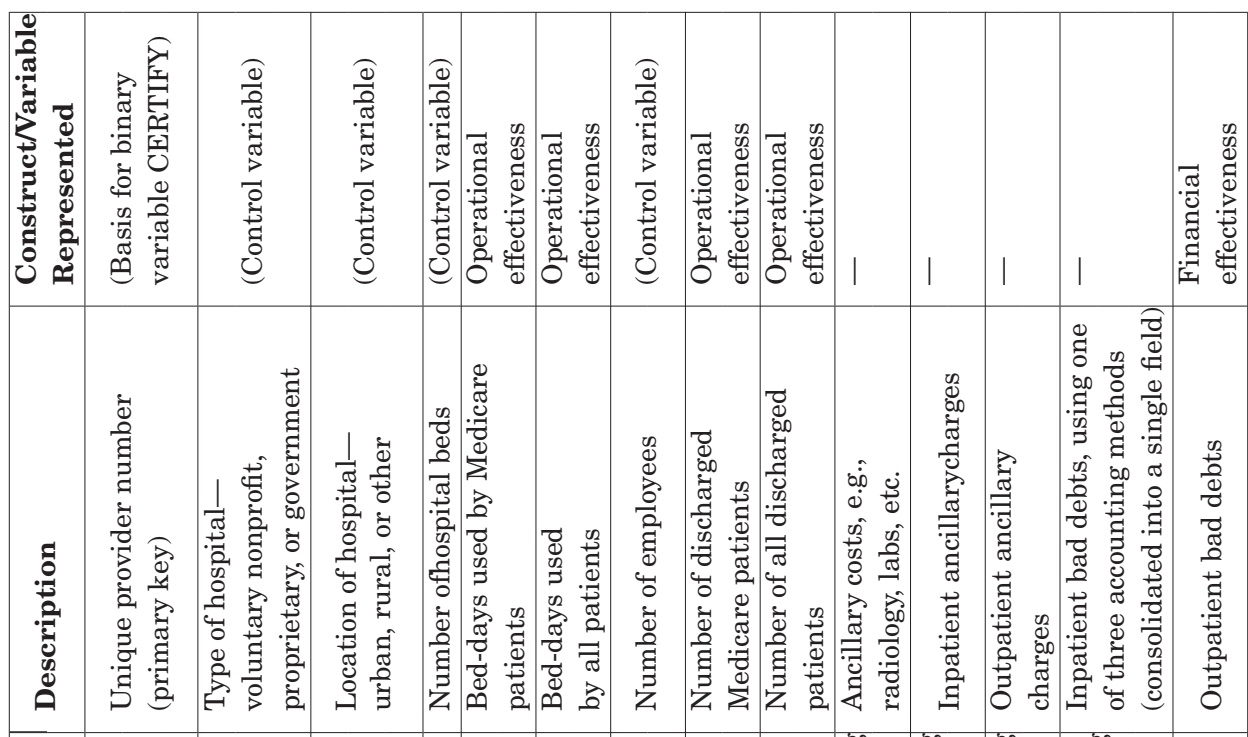

\begin{tabular}{|c|c|c|c|c|c|c|c|c|c|c|c|c|c|c|c|}
\hline & 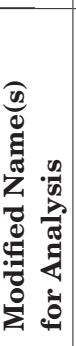 & $\begin{array}{l}\text { 是 } \\
\text { 足 } \\
\text { 出 }\end{array}$ & 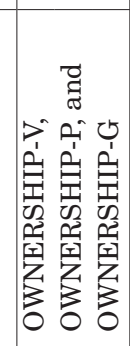 & 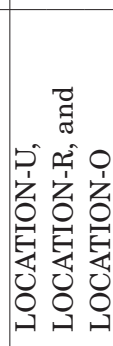 & 语 & $\begin{array}{l}\text { 氛 } \\
\text { 穴 } \\
\text { 空 }\end{array}$ & 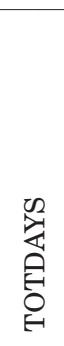 & 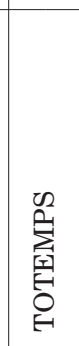 & 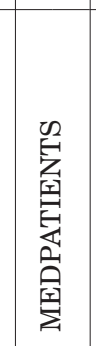 & 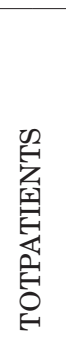 & 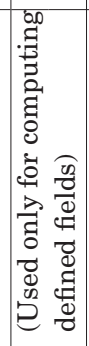 & 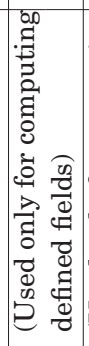 & 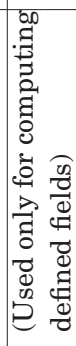 & 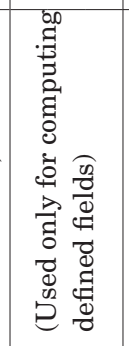 & $\begin{array}{l}\stackrel{-1}{\circ} \\
\text { 空 } \\
\text { 窝 } \\
0\end{array}$ \\
\hline & 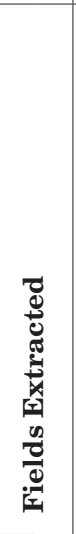 & Z & 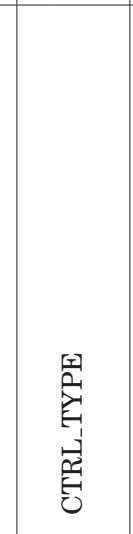 & 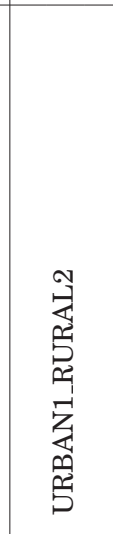 & 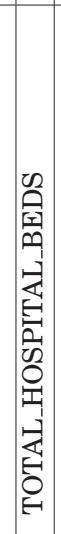 & 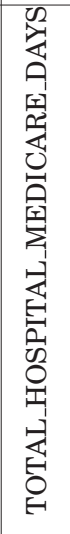 & 究 & 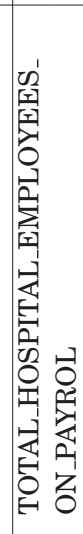 & 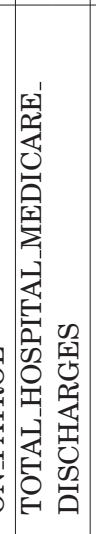 & 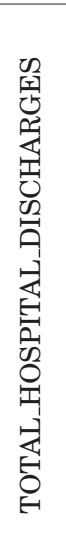 & 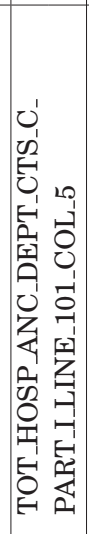 & 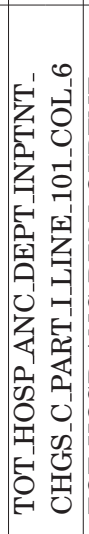 & 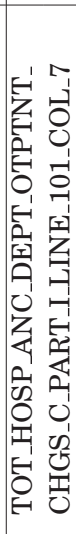 & 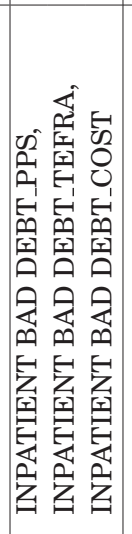 & 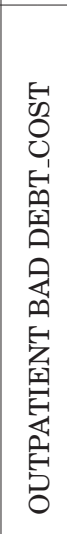 \\
\hline & 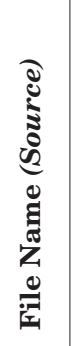 & 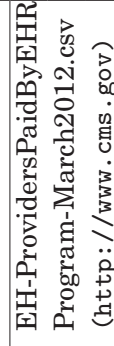 & 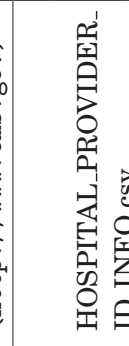 & 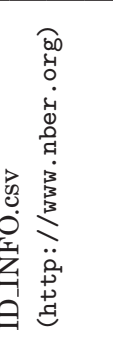 & & & 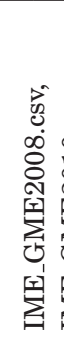 & 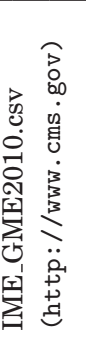 & & & & 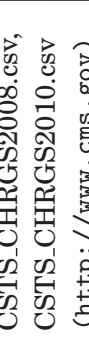 & & 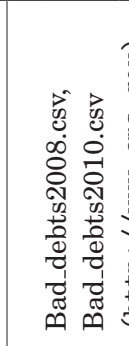 & \\
\hline
\end{tabular}




\section{B. Additional Data Items Defined and Computed from the Preceding Extracted Fields}

\begin{tabular}{|c|c|c|c|}
\hline Name & Computation & Description & $\begin{array}{l}\text { Construct/ } \\
\text { Variable } \\
\text { Represented }\end{array}$ \\
\hline CERTIFY & $\begin{array}{l}\text { Value of ' } 1 \text { ' for HOSPID values present in } \\
\text { source file EH-ProvidersPaidByEHR } \\
\text { Program-March2012.csv; } \\
\text { otherwise value of ' } 0 \text { ' }\end{array}$ & $\begin{array}{l}\text { '1' denotes } \\
\text { certified for } \\
\text { meaningful EHR } \\
\text { use }\end{array}$ & Certification \\
\hline BEDUTIL & $\begin{array}{l}\text { TOTAL_HOSPITAL_DAYS, divided by } \\
\text { (TOTAL_HOSPITAL_BEDS } \\
\text { times } 365 \text { ) }\end{array}$ & Bed utilization & $\begin{array}{l}\text { Operational } \\
\text { efficiency }\end{array}$ \\
\hline PROPMED & $\begin{array}{l}\text { TOTAL_HOSPITAL_MEDICARE_ } \\
\text { DAYS, divided by } \\
\text { TOTAL_HOSPITAL_DAYS }\end{array}$ & $\begin{array}{l}\text { Medicare bed } \\
\text { days, as a fraction } \\
\text { of total bed-days }\end{array}$ & $\begin{array}{l}\text { Operational } \\
\text { effectiveness }\end{array}$ \\
\hline STAYMED & $\begin{array}{l}\text { TOTAL_HOSPITAL_MEDICARE_ } \\
\text { DAYS, divided by } \\
\text { TOTAL_HOSPITAL_MEDICARE_ } \\
\text { DISCHARGES }\end{array}$ & $\begin{array}{l}\text { Days of stay per } \\
\text { Medicare patient }\end{array}$ & $\begin{array}{l}\text { Operational } \\
\text { efficiency }\end{array}$ \\
\hline STAYGEN & $\begin{array}{l}\text { TOTAL_HOSPITAL_DAYS, divided by } \\
\text { TOTAL_HOSPITAL_DISCHARGES }\end{array}$ & $\begin{array}{l}\text { Days of stay per } \\
\text { patient, for all } \\
\text { patients }\end{array}$ & $\begin{array}{l}\text { Operational } \\
\text { efficiency }\end{array}$ \\
\hline UNITCOSTS & $\begin{array}{l}\text { TOT_HOSP_ANC_DEPT_CTS_C_ } \\
\text { PART_I_LINE_101_COL_5, divided by } \\
\text { TOTAL_HOSPITAL_DISCHARGES }\end{array}$ & $\begin{array}{l}\text { Costs of ancillary } \\
\text { services (e.g., labs, } \\
\text { radiology, etc.), } \\
\text { per patient }\end{array}$ & $\begin{array}{l}\text { Financial } \\
\text { efficiency }\end{array}$ \\
\hline MARGIN & $\begin{array}{l}\text { (TOT_HOSP_ANC_DEPT_INPTNT } \\
\text { CHGS_C_PART_I_LINE_101_COL_6, } \\
\text { plus TOT_HOSP_ANC_DEPT_OTPTNT_ } \\
\text { CHGS_C_PART_I_LINE_101_COL_7, } \\
\text { minus TOT_HOSP_ANC_DEPT_CTS_C_ } \\
\text { PART_I_LINE_101_COL_5), divided by } \\
\text { TOT_HOSP_ANC_DEPT_CTS_C_ } \\
\text { PART_I_LINE_101_COL_5 }\end{array}$ & $\begin{array}{l}\text { Gross profit } \\
\text { margin from } \\
\text { ancillary services } \\
\text { only }\end{array}$ & $\begin{array}{l}\text { Financial } \\
\text { efficiency }\end{array}$ \\
\hline INDEBT & $\begin{array}{l}\text { INPATIENT BAD DEBT_PPS, plus } \\
\text { INPATIENT BAD DEBT_TEFRA, plus } \\
\text { INPATIENT BAD DEBT_COST }\end{array}$ & $\begin{array}{l}\text { Inpatient bad } \\
\text { debts }\end{array}$ & $\begin{array}{l}\text { Financial } \\
\text { effectiveness }\end{array}$ \\
\hline
\end{tabular}

\section{REFERENCES}

Angst, C. M. and Agarwal, R. 2009. Adoption of electronic health records in the presence of privacy concerns: The elaboration likelihood model and individual persuasion. MIS Quart. 33, 2, 339-370.

Anonymous. 2009. Lessons learned from a journey to EMR. Health Manag. Technol. 30, 11, 24-27.

Ayers, D. J., Menachemi, N., Ramamonjiarivelo, Z., Matthews, M., and Brooks, R. G. 2009. Adoption of electronic medical records: The role of network effects. J. Product Brand Manag. 18, 2, 127-135.

Blavin, F. E., Buntin, M. J., and Friedman, C. P. 2010. Alternative measures of electronic health record adoption among hospitals. Am. J. Manag. Care 16, 12, 293-301.

Charles, D., King, J., Patel, V., and Furukawa, M. F. 2013. Adoption of electronic health record systems among U.S. non-federal acute care hospitals: 2008-2012. ONC Data Brief, No. 9. Washington, D.C.: Office of the National Coordinator for Health Information Technology.

DesRoches, C. M., Worzala, C., Joshi, M. S., Kralovec, P. D., and Jha, A. K. 2012. Small, nonteaching, and rural hospitals continue to be slow in adopting electronic health record systems. Health Affairs 31, 5, 1092-1099.

DiMaggio, P. and Powell, W. 1983. The iron cage revisited: Institutional isomorphism and collective rationality in organizational fields. Am. Sociol. Rev. 4, 2, 147-160.

East, T. D. 2005. The EHR paradox. Frontiers Health Serv. Manag. 22, 2, 33-35.

El-Gayar, O., Deokar, A. V., and Wills, M. J. 2010. Evaluating task-technology fit and user performance for an electronic health record system. Int. J. Healthcare Technol. Manag. 11, 1, 50-65. 
Fareed, N., Ozcan, Y. A., and DeShazo, J. P. 2012. Hospital electronic medical record enterprise application strategies: Do they matter? Health Care Manag. Rev. 37, 1, 4-13.

Furukawa, M. F., Raghu, T. S., and Shao, B. B. M. 2010. Electronic medical records and cost efficiency in hospital medical-surgical units. Inquiry 47, 2, 110-123.

Ginn, G. O., Shen, J. J., and Moseley, C. B. 2011. Hospital financial position and the adoption of electronic health records. J. Healthcare Manage. 56, 5, 337-350.

Ginsburg, P. B. and Grossman, J. M. 2005. When the price isn't right: How inadvertent payment incentives drive medical care. Health Affairs 24, W5, 376-384.

Hamelburg, M. 2009. EHR and HIT incentives in the American Recovery and Reinvestment Act. Intell. Property Technol. Law J. 21, 6, 7-13.

Helton, J. and Hsu, C. E. 2012. Do EHR investments lead to lower staffing levels? J. Healthcare Financial Manag. 66, 2, 54-60.

Hennington, A., Janz, B., Amis, J., and Nichols, E. 2009. Understanding the multidimensionality of information systems use: A study of nurses' use of a mandated electronic medical record system. Commun. Assoc. Inform. Syst. 25, 1, 243-262.

Hillestad, R., Bigelow, J., Bower, A., Girosi, F., Meili, R., Scoville, R., and Taylor, R. 2005. Can electronic medical record systems transform health care? Potential health benefits, savings, and costs. Health Affairs 24, 5, 1103-1117.

Hochstadt, B. and Keyt, D. 2009. Health care IT: Supporting cost efficiencies in tough times. Benefits Quart. 25, 4, 7-9.

Hoffmann, L. 2009. Implementing electronic medical records. Commun. ACM 52, 11, 18-20.

Jensen, T. B., Kjærgaard, A., and Svejvig, P. 2009. Using institutional theory with sensemaking theory: A case study of information system implementation in healthcare. J. Inform. Technol. 24, 4, 343-353.

Jha, A. K., Desroches, C. M., Campbell, E. G., Donelan, K., Rao, S. R., Ferris, T. G., Shields, A., Rosenbaum, S., and Blumenthal, D. 2009. Use of electronic health records in U.S. hospitals. New England J. Med. $360,16,1628-1638$.

Kazley, A. S., Diana, M. L., and Menachemi, N. 2011. The agreement and internal consistency of national hospital EMR measures. Health Care Manag. Sci. 14, 4, 307-313.

Kazley, A. S., Diana, M. L., Ford, E. W., and Menachemi, N. 2012. Is electronic health record use associated with patient satisfaction in hospitals? Health Care Manage. Rev. 37, 1, 23-30.

Khoumbati, K. and Themistocleous, M. 2006. Evaluating integration approaches adopted by healthcare organizations. J. Comput. Inform. Syst. 47, 2, 20-27.

Kjerstad, E. 2003. Prospective funding of general hospitals in Norway: Incentives for higher production? Int. J. Health Care Finance Econ. 3, 4, 231-251.

MacKinnon, W. and Wasserman, M. 2009. Implementing electronic medical record systems. IT Prof. Mag. $11,6,50-53$.

Mannion, R., Marini, G., and Street, A. 2008. Implementing payment by results in the English NHS. J. Health Org. Manag. 22, 1, 79-88.

Naylor, M. D., Kurtzman, E. T., Grabowski, D. C., Harrington, C., McClellan, M., and Reinhard, S. C. 2012. Unintended consequences of steps to cut readmissions and reform payment may threaten care of vulnerable older adults. Health Affairs 31, 7, 1623-1632

Nov, O. and Schecter, W. 2012. Dispositional resistance to change and hospital physicians' use of electronic medical records: A multidimensional perspective. J. Am. Soc. Inform. Sci. Technol. 63, 4, 648-656.

O'Reilly, J., Busse, R., Häkkinen, U., Or, Z., Street, A., and Wiley, M. 2012. Paying for hospital care: The experience with implementing activity-based funding in five European countries. Health Econ. Policy Law 7, 1, 73-101.

Pfeffer, J. and Salancik, G. R. 1978. The External Control of Organizations: A Resource Dependence Perspective. Stanford Business Books.

Rogers, W. H., Draper, D., Kahn, K. L., Keeler, E. B., Rubenstein, L. V., Kosecoff, J., and Brook, R. H. 1990. Quality of care before and after implementation of the DRG-based prospective payment system: A summary of effects. J. Am. Med. Assoc. 264, 15, 1989-1994.

Schumacher, R. M. and Jerch, K. E. 2012. Measuring usability in healthcare IT: It's a practice, not a competition. Interactions 19, 4, 8-9.

Shin, D. Y., Menachemi, N., Diana, M., Kazley, A. S., Ford, E. W., and Allen, R. L. 2012. Payer mix and EHR adoption in hospitals. J. Healthcare Manag. 57, 6, 435-448.

Song, P. H., McAlearney, A. S., Robbins, J., McCullough, J. S., and Smith, B. T. 2011. Exploring the business case for ambulatory electronic health record system adoption. J. Healthcare Manag. 56, 3, 169-180. 
Swanson, A. and Lind, S. 2011. Usability testing EHRs: Examples from the front lines. Interactions 18, 6 , 54-58.

Terry, K. 2011. Are EHR incentives a waste of money? Informationweek. http://search.proquest.com/docview/899111609?.

Winston, E. R. and Medlin, B. D. 2011. Information technology implementation and adoption in relation to electronic medical records. J. Inform. Technol. Case Appl. Res. 13, 1, 43-59.

Wolf, L., Harvell, J., and Jha, A. K. 2012. Hospitals ineligible for federal meaningful-use incentives have dismally low rates of adoption of electronic health records. Health Affairs 31, 3, 505-513.

Zhivan, N. A. and Diana, M. L. 2012. U.S. hospital efficiency and adoption of health information technology. Health Care Manag. Sci. 15, 1, 37-47.

Received August 2012; revised June 2013, October 2013; accepted November 2013 